\title{
Factors associated to antidepressant prescription for civil servants of Belo Horizonte, MG
}

\author{
Renato Lopes Hurtado', Sérgia Maria Starling Magalhães ${ }^{1, *}$, Andréia Queiroz Ribeiro², Micheline \\ Rosa da Silveira ${ }^{1}$
}

\author{
${ }^{I}$ Department of Social Pharmacy, Faculty of Pharmacy, Federal University of Minas Gerais, ${ }^{2}$ Department of Nutrition and \\ Health, Federal University of Viçosa
}

\begin{abstract}
Selecting the most suitable drug for the treatment of depression has clinical and economic implications, since both safety and cost of antidepressants (AD) vary among therapeutic subgroups. This study aimed to evaluate the prescription of antidepressants for users of the pharmacy for civil servants of PBH (FARMASERV) in 2005. Univariate, bivariate and multivariate analyzes using logistic regression were performed. Of the total prescriptions analyzed (652), the majority were for women (81.7\%) and individuals aged between 19 and 59 years $(81.7 \%)$. The variables independently associated with the selection of AD were gender, age and the specialty of the prescriber. Women and young adults were more likely to be prescribed an SSRI compared to their congeners, with statistically significant differences. Psychiatrists were more likely to prescribe an SSRI than neurologists or general physicians. The determinant factors for selecting antidepressants may aid the planning of interventions aimed at patients and prescribers which can enable rationalization of the use of antidepressants.
\end{abstract}

Uniterms: Antidepressants/rational use. Depression/ treatment . Medicines/rational use.

A seleção adequada do medicamento para o tratamento da depressão tem implicações clínicas e econômicas, visto que a segurança e o custo dos antidepressivos (AD) variam entre as subclasses terapêuticas. Esse estudo avaliou prescrições de AD dispensadas em 2005 para usuários da Farmácia da Clínica dos Servidores da PBH (FARMASERV). Foram realizadas análises univariada, bivariada e multivariada dos dados, utilizando-se regressão logística. Do total de prescrições (652), a maioria era para mulheres $(81,7 \%)$ e para indivíduos com idade entre 19 e 59 anos $(81,7 \%)$. As variáveis independentemente associadas à seleção de $\mathrm{AD}$ foram gênero, faixa etária e especialidade do prescritor. Mulheres e adultos jovens têm maior chance de receber prescrição de ISRS, em comparação aos seus congêneres, sendo as diferenças estatisticamente significativas. A chance dos psiquiatras prescreverem ISRS é maior do que neurologistas e clínicos gerais. Os fatores determinantes da seleção do antidepressivo podem subsidiar o planejamento de intervenções dirigidas aos pacientes e prescritores de forma a permitir a racionalização de sua utilização.

Unitermos: Antidepressivos/uso racional. Depressão/terapia. Medicamentos/uso racional.

\section{INTRODUCTION}

Depression is a common, chronic, recurring medical condition frequently associated to functional disability and impairment to physical health. Depressed patients

\footnotetext{
*Correspondence: S. M. S. Magalhães. Departamento de Farmácia Social, Faculdade de Farmácia, Universidade Federal de Minas Gerais. Av. Antônio Carlos, 6627 - Pampulha - 31.270-901 - Belo Horizonte - MG, Brasil. E-mail sergiams@farmacia.ufmg.br
}

experience limitations to their activities and wellbeing as well as make greater use of the healthcare system (Fleck et al., 2003). The prevalence of depression and problems associated to the illness has enormous importance in the field of healthcare and is considered the fourth greatest health problem worldwide (Moussavi et al., 2007). The prevalence of depression in the general population ranges, on average, from 3 to $11 \%$ (Fleck et al., 2003). In Brazil, this prevalence may be as high as $12 \%$ (Valentini et al., 2004). Depression affects individuals of all ages, with a 
prevalence of about $5 \%$ in children and adolescents, reaching as high as $15 \%$ among individuals over 65 years of age, with a higher prevalence among middle-aged women (Vasa, Carlino, Pine, 2006; Harman et al., 2005; Ohayon, 2007).

The presupposition is that the main justification for the prescription of medication is an adequate diagnosis. Once the diagnosis is made, the choice of the most appropriate medication for treatment becomes a central problem. From the therapeutic standpoint, the use of medication is considered rational when the patient receives adequate medication for his/her clinical needs at therapeutic doses for the necessary length of time and at the lowest possible cost (Weilburg et al., 2004). Thus, assessing the rational use of antidepressants implies discussing these aspects of this class of medication.

A number of studies in the international literature have demonstrated that the main factors related to the choice of antidepressants are patient profile (especially with regard to age and the presence of co-morbidities), the safety of different classes of medication (which varies significantly in terms of the frequency and severity of adverse reactions), treatment cost and specialty of the prescriber (McManus et al., 2003; Sleath, Shih, 2003; Poluzzi et al., 2004). Further factors considered important in the choice of medication include the training to which the physician has been submitted, access to treatment protocols and pressure from the patients themselves for particular antidepressants (Sleath, Shih, 2003).

In Brazil, the choice of antidepressants is also a cause for concern as the clinical and economic consequences are important in the realm of public healthcare. However, a small number of studies on medication utilization focused on antidepressants have been conducted in the country. These studies are important to enable identification of problems and the establishment of the need for interventions for the rational use of these medications, thereby contributing toward improving the National Medication Policy.

The aim of the present study was to assess the prescription of antidepressants to users of the civil servants' pharmacy of the Municipal Government of Belo Horizonte (Minas Gerais, Brazil) in order to outline the profile of patients, prescribers and medications chosen, as well as to define determinants in the choice of antidepressant.

\section{MATERIALS AND METHODS}

\section{Study site}

The present study was carried out at FARMASERV - the pharmacy of the Civil Servants' Clinic (CLISERV) of the Municipal Government of Belo Horizonte (Minas Gerais, Brazil), linked to the Beneficence Agency (BEPREM) of the City of Belo Horizonte. BEPREM offers medical, dental and psychological services to over 40,000 civil servants and their dependents, comprising approximately 86,000 beneficiaries. CLISERV offers medical, dental and psychological care to municipal civil servants in a system of co-participation. Medications acquired from FARMASERV attract a $20 \%$ discount and the purchase is deducted from the civil servants' paychecks.

\section{Study design and population}

An observational, cross-sectional study was carried out focusing on all prescriptions for antidepressants issued at FARMASERV in 2005. FARMASERV has approximately 4,000 registered patients among the civil servants of the City of Belo Horizonte and their dependents. In 2005, 712 prescriptions for antidepressants were filled out, 652 (91.6\%) of which were included in the present study. Prescriptions repeated for the same patient were excluded.

\section{Variables analyzed}

The data sources used were the prescriptions of antidepressants acquired at FARMASERV and the BEPREM database. The information was organized on a collection form containing the following:

a) socioeconomic characteristics of the antidepressant user: gender (identified based on name), date of birth, occupation and monthly income. The work sector was only collected for the title holder (civil servant), as this information was not available for dependents. Monthly salary of the patient was that registered in the database. In the case of dependents (child or spouse), the income of the civil servant was considered the household income. In cases of other relationships of dependency, this datum could not be obtained;

b) characteristics of the prescriber and healthcare service: registered at the professional council for medical practitioners, and specialty as well as the healthcare service from which the prescription originated. The identification of the prescriber's specialty was performed based on information on the prescription or by means of a search of the electronic site of the respective medical council (CONSELHO, 2006). Specialties were divided into neurology, psychiatry, cardiology, general practice, endocrinology, pediatrics, gynecology and other medical specialties.

c) characteristics of medications prescribed: name and 
pharmacological class of the prescribed antidepressant. The following antidepressants commercialized by FARMASERV in 2005 were considered: selective serotonin reuptake inhibitors (SSRIs) - fluoxetine, sertraline, paroxetine, citalopram, escitalopram; non-selective monoamine reuptake inhibitors (NSMRIs) or tricyclic antidepressants - amitriptyline, nortriptyline, imipramine, clomipramine; others mirtazapine, bupropion, venlafaxine, maprotiline, moclobemide and trazodone. The classification of prescribed antidepressants was carried out based on the Anatomical Therapeutic Chemical Classification System.

Average treatment cost was calculated by taking the price listed at ABC FARMA during the month of purchase and subtracting the $20 \%$ discount. Monthly treatment cost was calculated based on the presentation and dosage of the prescription.

\section{Data collection}

Data collection took place between July and December 2006. During this collection period, each prescription was numbered sequentially. The collection form received the same numeration along with the patient's registered number at BEPREM, which allowed the identification of the work sector of the civil servant and whether the patient was the title holder or dependent.

\section{Data analysis}

The prescription was the unit of analysis. Frequency distribution was determined for the characteristics of the users, prescribers, healthcare service from which the prescription originated and the medications prescribed. The class of the prescribed antidepressant was the response variable - non-selective monoamine reuptake inhibitor (NSMRI) or selective serotonin reuptake inhibitor (SSRI). The following were the explicative variables: patient gender, age, occupation and monthly income; specialty of the prescriber; healthcare service from which the prescription originated; and treatment cost. Pearson's chi-square test and Fisher's exact test were employed for the bivariate analysis of the data. Independent associations between the variables and type of antidepressant prescribed were determined in the multivariate analysis using logistic regression. The criterion for inclusion of variables in the logistic model was based on an association with class of antidepressant at a level of $p<0.20$ in the bivariate analysis. The criterion for variables remaining in the final model was an association with class of antidepressant at a level of $p<0.05$. The odds ratio (OR) was used to measure associations (OR), presented as raw OR (when not controlling for confounding factors) and adjusted OR (when controlling for confounding factors). The Epi-Info 2000 and SAS 8.1 programs were employed in the statistical analyses. The study was conducted in compliance with the standards set forth in the Helsinki Declaration and received approval from the Research Ethics Committee of the Universidade Federal de Minas Gerais (Process no. 214/06).

\section{RESULTS}

Of the total number of prescriptions analyzed (652), $81.7 \%$ were for women and $16.9 \%$ for men, where in nine prescriptions this data was unavailable. The vast majority of patients were adults (69.2\%) (Table I). More than half of the prescriptions (for which it was possible to obtain information on the occupation of the user) were prescribed for educators and $35 \%$ for those with a monthly income seven times the minimum salary. The vast majority of prescriptions originated from a private healthcare service (78.4\%) and more than half of the antidepressants prescribed pertained to the selective serotonin reuptake inhibitor subgroup (Table I). Fluoxetine was the most commonly prescribed antidepressant, accounting for $28.4 \%$ of the prescriptions (185 cases). Among the tricyclic medications, nortriptyline was the most frequently used ( $14.4 \%$ of cases).

The average cost of treatment varied depending on the class of antidepressant. Treatment cost with SSRI was on average two-fold greater that that with NSMRI, which includes tricyclic antidepressants (Table II).

Table III displays the distribution of the chemicalpharmacological subgroup of the antidepressants described according to the selected variables. There were statistically significant differences in the selection of antidepressants with regard to user gender, age group, occupation and income. Women, young adults, educators and individuals with a monthly income more than seven times the minimum salary, had a greater likelihood of receiving a SSRI prescription. The specialty of the prescriber also appears to have a significant influence over the choice of antidepressant. Psychiatrists prescribed SSRI more than neurologists and general physicians (Table III). The healthcare services from which the prescription originated was not significantly associated with the type of antidepressant prescribed.

In a bid to select a statistical model that indicated the main determinants for the prescriptions, different models were tested, selecting the model with the best adjustment. Table IV displays the final results of the multivariate analysis. The following variables exhibited independent 
TABLE I - Characteristics of users, prescribers and medications prescribed. Pharmacy of the Civil Servants' Clinic (CLISERV) of the Municipal Government of Belo Horizonte, Minas Gerais, Brazil, 2005

\begin{tabular}{|c|c|c|}
\hline Variables & $\begin{array}{c}\text { Frequency } \\
n\end{array}$ & $\begin{array}{c}\text { Percentage } \\
\%\end{array}$ \\
\hline \multicolumn{3}{|l|}{ Age group of user } \\
\hline $1-18$ years & 22 & 3.4 \\
\hline $19-59$ years & 451 & 69.2 \\
\hline $60-69$ years & 79 & 12.1 \\
\hline \multicolumn{3}{|l|}{ Occupation of user } \\
\hline Retired & 74 & 11.3 \\
\hline Educator & 174 & 26.7 \\
\hline Healthcare professional & 55 & 8.4 \\
\hline Administrative professional & 19 & 2.9 \\
\hline Other & 14 & 2.1 \\
\hline \multicolumn{3}{|l|}{ Income of user* } \\
\hline$<4$ times the minimum salary & 201 & 30.8 \\
\hline 4-7 times the minimum salary & 124 & 19.0 \\
\hline$>7$ times the minimum salary & 228 & 35.0 \\
\hline \multicolumn{3}{|l|}{ Specialty of prescriber } \\
\hline Psychiatrist & 217 & 33.3 \\
\hline Neurologist & 54 & 8.3 \\
\hline General physician & 89 & 13.7 \\
\hline Other & 171 & 26.2 \\
\hline \multicolumn{3}{|l|}{$\begin{array}{l}\text { Therapeutic subgroup of } \\
\text { antidepressant prescribed }\end{array}$} \\
\hline $\mathrm{NSMRI}^{* *}$ & 200 & 30.7 \\
\hline $\operatorname{SSRI}^{* * *}$ & 374 & 57.4 \\
\hline Others $^{* * * *}$ & 78 & 12.0 \\
\hline
\end{tabular}

*value of minimum salary during the period of the study (2005): R\$300.00; ** NSMRI: non-selective monoamine reuptake inhibitor (tricyclic antidepressant); ${ }^{* * *}$ SSRI: selective serotonin reuptake inhibitor; ${ }^{* * *}$ Others: atypical antidepressants that do not fit under the above classifications associations with the prescription of SSRIs: psychiatric specialty $(\mathrm{OR}=3.67 ; 95 \%$ CI 1.28 - 10.54); age between 19 and 59 years $(\mathrm{OR}=2.78 ; 95 \% \mathrm{CI}=1.10-7.0)$ and female gender $(\mathrm{OR}=2.42 ; 95 \% \mathrm{CI}=1.1-5.54)$.

\section{DISCUSSION}

The population treated during the study period had a diverse profile with regard to socio-demographic characteristics such as age, monthly income and occupation. The greater frequency of women and the fact that over $80 \%$ of the population was within the economically active age group, are findings that are in agreement with studies carried out in a number of countries (Ohayon, 2007; Bellantuono et al., 2002). These findings demonstrate that this is the portion of the population at the highest risk for the development of depressive disorders in Brazil. The most prominent group comprised civil servants who exercised teaching activities, followed by retirees. Although not representative of the civil service population in the Municipal Government of Belo Horizonte (Minas Gerais, Brazil), this fact is of considerable importance as it corroborates other studies showing educators are subject to various stress factors that result in a greater prevalence of mental problems (Santos, Kassouf, 2007; Reis et al., 2006; Araújo et al., 2005). In a study involving a population of educators in the public school system of the city of Belo Horizonte, Gasparini, Barreto, Assunção (2005) found that mental disorders were significantly associated with the violence and stressful work conditions teachers face. The results of the present study suggest that this subgroup is more susceptible to developing depressive disorders. Studies on medication utilization may serve as tools for assessing the prevalence of morbidities in specific populations. As mental disorders are known to be a common cause of sick leave in the public school system, such studies allow estimation of the prevalence of individuals affected by this condition and, if necessary, the need for early interventions that can reduce the severity and minimize the need for sick leave. It should be stressed, however, that the viability of

TABLE II - Monthly treatment cost (R\$) according to therapeutic subgroup of antidepressant prescribed. Pharmacy of the Civil Servants' Clinic (CLISERV) of the Municipal Government of Belo Horizonte, Minas Gerais, Brazil, 2005

\begin{tabular}{lccccc}
\hline Therapeutic subgroup of antidepressant & $\mathbf{n}$ & Mean $( \pm \mathbf{S D})$ & Minimum & Median & Maximum \\
\hline NSMRI $^{*}$ & $195^{* * *}$ & $21.9(28.3)$ & 4.7 & 17.1 & 252.8 \\
SSRI $^{* *}$ & 374 & $44.8(26.7)$ & 7.8 & 41.4 & 218.6 \\
Others & 78 & $101.35(47.28)$ & 37.5 & 96.17 & 280.8 \\
\hline
\end{tabular}

"NSMRI: non-selective monoamine reuptake inhibitor (tricyclic antidepressant); ${ }^{* *}$ SSRI: selective serotonin reuptake inhibitor; ${ }^{* * * *}$ It was not possible to obtain the sales price of the medication for 5 prescriptions. 
TABLE III - Subgroup of antidepressants prescribed according to selected characteristics. Pharmacy of the Civil Servants' Clinic (CLISERV) of the Municipal Government of Belo Horizonte, Minas Gerais, Brazil, 2005

\begin{tabular}{|c|c|c|c|}
\hline \multirow[t]{2}{*}{ Variables } & \multicolumn{2}{|c|}{ Antidepressant } & \multirow[t]{2}{*}{ Significance } \\
\hline & NSMRI $(\%)^{*}$ & SSRI $(\%)^{* *}$ & \\
\hline \multicolumn{4}{|l|}{ Gender of user } \\
\hline Male & $52(26.5)$ & $43(11.6)$ & \\
\hline Female & $144(73.5)$ & $327(88.4)$ & $\mathrm{p}<0.01$ \\
\hline \multicolumn{4}{|l|}{ Age group of user } \\
\hline $1-18$ years & $15(9.7)$ & $7(2.1)$ & \\
\hline $19-59$ years & $103(66.4)$ & $285(86.6)$ & \\
\hline $60-69$ years & 37 (23.9) & $37(11.3)$ & $\mathbf{p}<0.01$ \\
\hline \multicolumn{4}{|l|}{ Occupation of user } \\
\hline Retired & $26(32.9)$ & $38(18.5)$ & \\
\hline Educator & $30(38.0)$ & $113(55.1)$ & \\
\hline Healthcare professional & $8(10.1)$ & $36(17.6)$ & \\
\hline Administrative professional & $10(12.7)$ & $9(4.4)$ & \\
\hline Other & $5(6.3)$ & $9(4.4)$ & $\mathrm{p}<0.01$ \\
\hline \multicolumn{4}{|l|}{ Income of user } \\
\hline$<4$ times the minimum salary & $73(46.5)$ & $115(35.2)$ & \\
\hline 4-7 times the minimum salary & $37(23.6)$ & $65(19.9)$ & \\
\hline$>7$ times the minimum salary & $47(29.9)$ & $147(44.9)$ & $\mathrm{p}<0.01$ \\
\hline \multicolumn{4}{|l|}{ Specialty of prescriber } \\
\hline Neurologist & $39(31.7)$ & $14(7.3)$ & \\
\hline Psychiatrist & $49(39.8)$ & $132(68.7)$ & \\
\hline General physician & $35(28.5)$ & $46(24.0)$ & $\mathrm{p}<\mathbf{0 . 0 1}$ \\
\hline
\end{tabular}

"NSMRI: non-selective monoamine reuptake inhibitor (tricyclic antidepressant); ${ }^{* *}$ SSRI: selective serotonin reuptake inhibitor; ${ }^{* * *}$ Pearson's Chi-square test $\left(\chi^{2}\right)$ for comparisons between prescription of NSMRI and SSRI

TABLE IV - Results of the multivariate analysis of determinants for prescribing antidepressants purchased from the Pharmacy of the Civil Servants' Clinic (CLISERV) of the Municipal Government of Belo Horizonte, Minas Gerais, Brazil, 2005

\begin{tabular}{lcccc}
\hline Variables & \multicolumn{2}{c}{ Raw } & \multicolumn{2}{c}{ Adjusted } \\
\cline { 2 - 5 } & OR & $95 \%$ CI & & $95 \%$ CI \\
\hline Specialty of prescriber & & & & \\
Neurologist* & & & 2.33 & $0.75-7.17$ \\
General physician & 3.66 & $1.62-8.36$ & 3.67 & $1.28-10.54$ \\
Psychiatrist & 7.50 & $3.57-15.97$ & & \\
Age group & & & 2.78 & $1.10-7.00$ \\
60 years or more* & 2.77 & $1.61-4.74$ & 1.04 & $0.13-8.25$ \\
19-59 years & 0.47 & $0.15-1.41$ & & \\
$1-18$ years & & & 2.42 & $1.06-5.55$ \\
Gender & 2.75 & $1.71-4.41$ & & \\
Female & & &
\end{tabular}

*reference category

this strategy largely depends upon ensuring that the acquisition of medications by municipal civil servants occurs at FARMASERV, a factor the present study was unable to verify. The relatively low number of prescriptions filled out during the period suggests that the acquisition of me- dication does not occur at FARMASERV for the most part, which may be explained by the lower cost of medications obtained at commercial pharmacies achieved by on-site manufacturing blending as well as those obtained through the public healthcare system. 
Regarding income, the present study identified that the predominant use of antidepressants - and presumably predominant occurrence of depression - was not greater among those with lower incomes. However, this analysis was limited by the fact that FARMASERV is located in an upper class region in the city of Belo Horizonte, which could have hampered access to individuals with lower incomes, who generally reside in the outlying areas of large cities in Brazil. Furthermore, medical appointments at CLISERV are not free of charge, which limits the use of the service by civil servants on lower incomes.

The distribution of prescribers was concentrated in private healthcare services and at CLISERV. Thus, the present study provides insights on the prescription habits in the private healthcare system, which is often of difficult access and where there are no limitations imposed by standardization of medications. The care profile is consistent with the data on the income of the population studied. One may presume that individuals on higher incomes have a greater likelihood of using private healthcare services. Workers on low incomes generally tend to utilize public healthcare services, where they can also gain access to medications. Thus, one limitation of the present study is that the results cannot be generalized for the population of municipal civil servants in the city of Belo Horizonte, as those that use the public healthcare system may be under-represented.

The distribution profile of the most prescribed medications raises questions regarding the determinants of this choice. According to the literature, there is equivalence in terms of the effectiveness of SSRI and tricyclic classes but considerable variation with regard to safety (Geddes et al., 2000). A number of studies indicate fluoxetine as the most often prescribed antidepressant (Ohayon, 2007; Andrade, Andrade, Santos, 2004). Fluoxetine has taken on an emblematic role in the mind of the public as an instrument for achieving a state of satisfaction and emotional balance (Rodrigues, 2003). Although a completely mistaken notion, this fact may have an important influence on the prescribers. Another explanation for the extensive use of fluoxetine is its anorectic property, which may lead to its prescription for this purpose. It should be stressed that some SSRIs are available in their magistral formula. As FARMASERV does not perform on-site medicine compounding, the present study did not address this type of prescription.

Psychiatrists were the main prescribers in the present study. General physicians occupied second place, ahead of neurologists. It should be stressed that, at private healthcare services, patients have greater access to specialists, which may contribute toward the greater frequency of prescriptions by psychiatrists and neurologists.

Cost is nearly always one of the determinants in the choice of medications and is one of the prescription rationality criteria. It is clearly evident that tricyclic medications (NSMRIs) are nearly half the price of SSRIs. However, their worse safety profile limits their use. The other classes (others) are much more costly. This considerable variation in price is also seen within a single class. Among the SSRIs, the price of fluoxetine is much lower than the other medications in this class.

The fact that neurologists were the specialists that most prescribed tricyclic medications suggests that they deal with more complex cases of depression or an association between depression and other pathologies or even other conditions for which tricyclics are therapeutic options. In such cases, prescriptions from neurologists should be evaluated with caution, particularly with regard to medication interactions, as these patients potentially take multiple medications with shared adverse reactions and possible interactions between one another. Possibly due to their lesser experience in managing depression, general physicians revealed a preference for prescribing SSRIs, which are safer drugs with fewer side effects. This finding was also described in a study carried out by McManus et al. (2003).

The investigation into associations between age and the choice of antidepressant was motivated by the greater vulnerability of children and elderly individuals to the adverse effects of drugs. For example, there are numerous accounts in the literature stating that SSRIs are the safest class of antidepressants for use in elderly individuals (Scalco, 2002). It is possible a portion of the tricyclic antidepressants prescribed for children and adolescents were indicated for the treatment of conditions unrelated to depression, such as nocturnal enuresis and other clinical pictures commonly found in this age group (Wagner, 2005). In the treatment of depressive disorders, a possible implication of SSRIs in childhood-teenage suicide may also have influenced this choice. The predominant prescription of SSRIs for young adults was expected due to the effectiveness and safety offered by this class of medication. In the multivariate analysis, a younger age did not prove to be a determinant in the choice of the class of antidepressant prescribed. It is possible that the low frequency of prescriptions for children and adolescents limited the power of the study regarding the analysis of this variable. Only when comparing the 19-to59 -year-old age group to elderly individuals was there a greater chance of prescribing a SSRI for the former. It is possible that a portion of the prescriptions of tricyclic antidepressants was for the treatment of conditions other than depression in elderly individuals. This finding is worrisome, considering the risks of the use of this class of antidepressant for the elderly. Such concerns include the risk of falls due to orthostatic hypotension, cardiovascular and anticholinergic 
problems and the risk of intoxication due to difficulties in metabolizing and excreting the drug as well as the greater incidence of adverse reactions and medication interactions (Scalco, 2002; Fick et al., 2003). However, as the present study was not specifically designed to test differences in the prescription of antidepressants between age groups, such aspects should be considered with reservation. The findings speak to the need for an in-depth study on the profile of antidepressant prescriptions for elderly individuals in the city of Belo Horizonte (MG, Brazil).

Women were more likely to be prescribed SSRIs in comparison to men. This result corroborates findings described in previous studies (Ohayon, 2007; Rentsch et al., 2007; Weissman et al., 1996). It is likely that the explanation for this association is the adverse effects of this class of antidepressant on sexuality, such as inhibition of libido, and anorgasmia (Mann, 2005). It is possible that men have a greater resistance to experiencing these side effects and, as such, prescribers do not choose this class for men due to the risk of a lesser adherence to treatment.

There was greater prescription of SSRIs across all income groups, including the group with a monthly income of less than four times the minimum salary. It is likely that only those patients treated through the Brazilian public healthcare system and those who received prescriptions for non-standardized medications from the municipal public healthcare services (in the case of SSRIs) resorted to FARMASERV to fill out their prescriptions, which would explain this result. This hypothesis was indicated in the bivariate analysis, in which there was an association between class of antidepressant prescribed and patient monthly income. However, the association was not maintained in the multivariate analysis.

The present study has limitations that should be addressed, including the unavailability of inaccessible data in the databases and documentation used, as well as the small sample, which precludes the extrapolation of findings to other populations. However, the importance of the study should be stressed, namely, the identification of associations that may contribute toward the proposal of interventions that allow the rationalization of the treatment of depression and prevention of problems related to antidepressant medications.

In summary, the present study provides insights into habits regarding the prescription of antidepressants in the city of Belo Horizonte that were filled out at FARMASERV. The panorama observed stresses the popularity of selective serotonin reuptake inhibitors and highlights important aspects for the rationalization of the use of antidepressants. The prescription of tricyclic medications, particularly in neurology, is possibly the aspect of greatest clinical importance, as these drugs should be used with caution due to their safety profile. Tricyclics were chosen for elderly individuals - thereby going against recommendations in the literature (Scalco, 2002, Fick et al., 2003) - as this class is known to have a more affordable price in comparison to SSRIs, this is an important observation. Cost is one of the determinants in the choice of medications and treatment decisions need to be based on considerations of relative patient acceptability, toxicity and cost. However, further studies are needed in order to monitor safety and the implications for morbidity and quality of life particularly among elderly individuals who use this class of medication. Thus, studies on pharmacovigilance are of considerable importance to this subgroup of the population. Moreover, the reasons for which tricyclics are the medication of choice for the elderly should be further investigated.

\section{REFERENCES}

ANDRADE, M. F.; ANDRADE, R. C. G; SANTOS, V. Prescrição de psicotrópicos: informações contidas em receitas e notificações. Rev. Bras. Cienc. Farm., v.40, n.4, p.471-479, 2004.

ARAÚJO, T. M.; SENA, I. P.; VIANA, M. A.; ARAUJO, E. M. Mal-estar docente: Avaliação de condições de trabalho e saúde em uma instituição de ensino superior. Rev. Baiana de Saúde Públ., v.29, n.1, p.6-21, 2005.

BELLANTUONO, C.; MAZZI, M. A.; TANSELLA, M.; RIZZO, R.; GOLDBERG, D. The identification of depression and the coverage of antidepressant drug prescriptions in Italian general practice. J. Affect. Disord., v.72, n.1, p.53-59, 2002.

CONSELHO REGIONAL DE MEDICINA DE MINAS GERAIS. Available at: < http://www.portalmedico.org.br/ index.asp $>$. Accessed on: 13 sept. 2006.

FICK, D. M.; COOPER, J. W.; WADE, W. E.; WALLER, J. L.; MACLEAN, J. R.; BEERS, M. H. Updating the Beers criteria for potentially inappropriate medication use in older adults: results of a US consensus panel of experts. Arch. Intern. Med., v.163, n.22, p.2716-2724, 2003.

FLECK, M. P. A.; LAFER, B.; SOUGEY, E. B.; PORTO, J. A. D.; BRASIL, M. A.; JURUENA, M. F. Diretrizes da Associação Médica Brasileira para o tratamento de depressão (versão integral). Rev. Bras. Psiquiatr., v.25, n.2, p.114-122, 2003. 
GASPARINI, S. M.; BARRETO, S. M.; ASSUNÇÃO, A. A. O professor, as condições de trabalho e os efeitos sobre sua saúde. Educ. Pesqui., v.31, n.2, p.189-199, 2005.

GEDDES, J. R., FREEMANTLE, N., MASON, J., ECCLES, M. P., BOYNTON, J. SSRIs versus other antidepressants for depressive disorder. Cochrane Database Syst. Rev., v.2, CD001851, 2000. Review. Update in: Cochrane Database Syst. Rev. v.3, CD001851, 2006.

HARMAN, J. S.; EDLUND, M. J.; FORTNEY, J. C.; KALLAS, $\mathrm{H}$. The influence of comorbid chronic medical conditions on the adequacy of depression care for older Americans. $J$. Am. Geriatr. Soc., v.53, n.12, p.2178-2183, 2005.

MANN, J. J. The medical management of depression. N. Engl. J. Med., v.353, n.17, p.1819-1834, 2005.

MCMANUS, P.; MANT, A.; MITCHELL, P.; BRITT, H.; DUDLEY, J. Use of antidepressants by general practitioners and psychiatrists in Australia. Aust. N. Z. J. Psychiatry, v.37, n.2, p.184-189, 2003.

OHAYON, M. M. Epidemiology of depression and its treatment in the general population. J. Psychiatr. Res., v.41, n.3-4, p.207-213, 2007.

POLUZZI, E.; MOTOLA, D.; SILVANI, C.; DE PONTI, F.; VACCHERI, A.; MONTANARO, N. Prescriptions of antidepressants in primary care in Italy: pattern of use after admission of selective serotonin reuptake inhibitors for reimbursement. Eur. J. Clin. Pharmacol., v.59, n.11, p.825-831, 2004.

REIS, E. J. F. B.; ARAUJO, T. M.; CARVALHO, F. M.; BARBALHO, L.; SILVA, M. O. Doença e exaustão emocional. Educ. Soc., v.27, n.94, p.229-253, 2006.

RENTSCH, M. D.; DUMONT, P.; BORGACCI, M. D. S.; CARBALLEIRA, M. D. Y.; DE TONNAC, M. D. N., ARCHINARD, M. D. M. ; ANDREOLLI, A. Prevalence and treatment of depression in a hospital department of internal medicine. Gen. Hosp. Psychiatry, v.29, n.1, p.2531,2007

RODRIGUES, J. T. Psicologia em Estudo. A medicação como única resposta: uma miragem do contemporâneo. Psicol. Estud., v.8, n.1, p.13-22, 2003.
SANTOS, M. J.; KASSOUF, A. L. Uma investigação dos determinantes socioeconômicos da depressão mental no Brasil com ênfase nos efeitos da educação. Econ. Aplic., v.11, n.1, p.5-26, 2007.

SCALCO, M. Z. Tratamento de idosos com depressão utilizando antidepressivos tricíclicos, IMAO, ISRS e outros antidepressivos. Rev. Bras. Psiquiatr., v.24, supl.1, p.55-63, 2002.

MOUSSAVI, S; CHATTERJI, S; VERDES, E; TANDON, A; PATEL, V; USTUN, B. Depression, chronic diseases, and decrements in health: results from the World Health Surveys. Lancet, v. 370, n. 9590, p. 851-858, 2007.

SLEATH, B.; SHIH, Y. T. Sociological influences on antidepressant prescribing. Soc. Sci. Med., v.56, n.6, p.1335-1344, 2003.

VALENTINI, W.; LEVAV, I.; KOHN, R.; MIRANDA, C. T.; MELLO, A. A. F.; MELLO, M. F.; RAMOS, C. P. Treinamento de clínicos para o diagnóstico e tratamento da depressão. Rev. Saúde Públ., v.38, n.4, p.522-528, 2004.

VASA, R. A.; CARLINO, A. R.; PINE, D. Pharmacotherapy of depressed children and adolescents: current issues and potential directions. Biol. Psychiatry, v.59, n.11, p.10211028, 2006.

WAGNER, K. D. Pharmacotherapy for major depression in children and adolescents. Prog. Neuropsychopharmacol. Biol. Psychiatr., v.29, n.5, p.819-826, 2005.

WEILBURG, J.; STAFFORD, R. S.; O’LEARY, K. M.; MEIGS, J. B.; FINKELSTEIN, S. N. Costs of antidepressant medications associated with inadequate treatment. Am. J. Manag. Care, v.10, n.6, p.357-365, 2004.

WEISSMAN, M. M.; BLAND, R. C.; CANINO G, FARAVELLI, G. J.; GREENWALD, S; HWU, H. G.; JOYCE, P. R.; KARAM, E. G.; LEE, C. K.; LELLOUCH, J.; LEPINE, J. P.; NEWMAN, S. C.; RUBIO-STIPEC, M.; J WELLS, E.; WICKRAMARATNE, P. J.; WITTCHEN, H.; YEH, E. K. Cross-national epidemiologic of major depression and bipolar disorder. JAMA, v.276, n.4, p.293-299, 1996.

Received for publication on $14^{\text {th }}$ May 2009 Accepted for publication on $16^{\text {th }}$ November 2009 